\title{
RETRACTED ARTICLE: A Family of Finsler Metrics Projectively Related to a Randers Metric
}

\author{
A. Tayebi, E. Peyghan and H. Sadeghi
}

Using a false email account, somebody submitted a fake positive report, thereby deliberately misleading the Managing Editor of Results in Mathematics. The Managing Editor accepted the paper based upon this report, which he assumed had been written by a well-known expert in Finsler geometry. This involves a violation of our publishing policies at the highest possible level. The Managing Editor and the Publisher have therefore decided to retract the paper and apologize to the readers of Results in Mathematics that this infringement was not picked up earlier.

\author{
A. Tayebi and H. Sadeghi \\ Department of Mathematics \\ University of Qom \\ Qom, Iran \\ e-mail: akbar.tayebi@gmail.com \\ H. Sadeghi \\ e-mail: sadeghihassan64@gmail.com \\ E. Peyghan \\ Department of Mathematics \\ Faculty of Science \\ Arak University, Arak 38156-8-8349, Iran \\ e-mail: epeyghan@gmail.com
}

Received: February 23, 2012.

Accepted: March 17, 2012. 